\title{
Differentiatie in het curriculum diergeneeskunde door middel van studiepaden
}

\author{
Winnende poster op het NVMO-congres 2001
}

P. van Beukelen, D. Wesseling, J.C.M. Haarhuis, L.M.G. van Golde

\section{Samenvatting}

Inleiding: In de diergeneeskundige beroepsuitoefening vindt een sterke differentiatie plaats naar diersoort en sector. Bij individueel gehouden dieren ligt de nadruk op curatieve aspecten en bij landbouwhuisdieren op preventie en volksgezondheidsaspecten. Dit was aanleiding om het curriculum van de Faculteit der Diergeneeskunde in Utrecht te vernieuwen.

Beschrijving: In het vernieuwde curriculum dat in 1995 startte, is de differentiatie beperkt tot diersoortspecifieke co-assistentschappen in jaar 6. In september 2001 is een verdere vernieuwing ingevoerd met meer nadruk op 'academisering' en meer differentiatie. Dit laatste wordt bereikt door invoering van gescheiden studiepaden. In jaar één kiezen de studenten uit twee studiepaden: 'Individueel gehouden dieren' of 'Veterinaire volksgezondheid/landbouwhuisdieren'. In de hogere studiejaren worden deze studiepaden verder uitgesplitst. Uiteindelijk zijn er zes uitstroomprofielen. De studiepunten zijn als volgt verdeeld: kerncurriculum 159; studiepaden 83 en vrije keuzeruimte 10 studiepunten. Met voorbeelden wordt toegelicht hoe per vak de studiepunten verdeeld kunnen zijn over kerncurriculum en verschillende studiepaden.

Studenten die toegelaten worden via decentrale selectie binden zich aan het studiepad 'Veterinaire volksgezondheid/landbouwhuisdieren'. De overige studenten kiezen een studiepad aan het eind van het eerste trimester.

In het beroepsveld worden erkenningsregelingen per diersoort of sector opgezet met instroomeisen die gekoppeld zijn aan de verschillende studiepaden.

Discussie: De Faculteit der Diergeneeskunde denkt met het nieuwe curriculum goed in te spelen op de veranderde behoeftes in het beroepsveld. Zowel curriculum 1995 als curriculum 2001 worden geëvalueerd. Differentiatie door middel van studiepaden zou een voorbeeld kunnen zijn voor differentiatie in andere medische opleidingen. (Beukelen P van, Wesseling D, Haarhuis JCM, Golde LMG van. Studiepaden voor differentiatie in het curriculum diergeneeskunde. Tijdschrift voor Medisch Onderwijs 2002;21(4):154-160.)

\section{Inleiding}

De Faculteit der Diergeneeskunde in Utrecht is de enige faculteit in Nederland waar dierenartsen worden opgeleid. In de werkzaamheden van praktiserende dierenartsen is de afgelopen decennia een sterke differentiatie opgetreden. Tot twintig à dertig jaar geleden behandelden de meeste dierenartsen in principe alle gedomesticeerde diersoorten. De nadruk lag daarbij op het individuele zieke dier en het curatieve aspect. Tegenwoordig beperken de meeste dierenartsen zich tot één of hooguit enkele diersoorten. Wat betreft de diergeneeskundige zorg wordt er een duidelijk onderscheid gemaakt tussen individueel gehouden dieren en landbouwhuisdieren. De eerste groep bestaat uit de gezelschapsdieren (hond, kat, konijn, et cetera) en het paard, terwijl de groep landbouwhuisdieren bestaat uit dieren die gehouden worden ten behoeve van de 
voedselproductie, zoals herkauwers, varkens en pluimvee. Bij de individueel gehouden dieren ligt de nadruk van de zorg nog steeds op het individuele zieke dier. Deze sector van de diergeneeskunde volgt de ontwikkelingen in de humane geneeskunde. Bij de landbouwhuisdieren ligt de nadruk op het preventieve aspect. De dierenarts zorgt voor de gezondheid en het welzijn van productiedieren. Daarnaast speelt de praktiserende dierenarts een belangrijke rol in het bewaken van de volksgezondheid door een bijdrage te leveren aan de preventie van microbiologische en chemisch-toxische contaminaties (onder andere antibiotica) van voedingsmiddelen van dierlijke oorsprong. Ruim twee derde van de Nederlandse dierenartsen is werkzaam in de praktijk. Een groot deel van de niet-praktiserende dierenartsen houdt zich bezig met de veterinaire volksgezondheid (Rijksdienst voor de Keuring van Vee en Vlees, ministerie van Landbouw, Natuurbeheer en Visserij, ministerie van Volksgezondheid, Welzijn en Sport en onderzoeksinstituten).

In het diergeneeskundecurriculum is de afgelopen jaren ingespeeld op de toenemende differentiatie in het beroepsveld. ${ }^{1}$ In september 1995 is een nieuw curriculum ingevoerd met differentiatie in het zesde jaar. Hierop voortbouwend is het curriculum verder vernieuwd, met meer nadruk op 'academisering' en differentiatie vanaf het eerste jaar. In dit artikel wordt Curriculum 1995 beschreven en in aansluiting daarop de redenen om verdere vernieuwingen in te voeren. Hoe door de invoering van studiepaden vorm gegeven wordt aan verdere differentiatie is het belangrijkste thema in de beschrijving van Curriculum 2001. Ook wordt kort ingegaan op de afstemming tussen de studiepaden en de erkenningsregelingen in het beroepsveld.

\section{Curriculum 1995}

De doelstellingen van Curriculum 1995 zijn:

- verkrijgen van probleemoplossende vaardigheden;

- verkrijgen van sociale en communicatieve vaardigheden;

- verwerven van een academisch denk- en werkniveau;

- verkrijgen van een diersoortgerichte startcompetentie voor de eerstelijns praktijkuitoefening;

- bewustwording van het belang van levenslang leren. ${ }^{2} 3$

$\mathrm{Na}$ de vierjarige doctorale fase, waarin de nadruk ligt op het verwerven van cognitieve vaardigheden in kleinschalig onderwijs, volgt een tweejarige functiegerichte fase. In het vijfde studiejaar doorlopen alle co-assistenten de uniforme co-assistentschappen en een onderzoeksstage. Deze uniforme co-assistentschappen duren dertig weken. Daarin doen de coassistenten basale vaardigheden op met alle voor de dierenarts relevante diersoorten. De nadruk ligt op vaardigheden die van belang zijn voor de eerste opvang van patiënten. Het zesde studiejaar is gereserveerd voor diersoortspecifieke co-assistentschappen. De co-assistent maakt halverwege het vijfde jaar een keuze ten aanzien van dit co-assistentschap.

\section{Redenen voor verdere vernieuwingen}

Het Curriculum 1995 bevat veel, grotendeels kleinschalig contactonderwijs. Het curriculum is schoolser geworden dan beoogd en verwacht werd, waardoor het niet goed aansluit bij het studiehuis. De ontwikkelingen in de diergeneeskunde gaan zo snel dat differentiatie in één studiejaar, zoals in Curriculum 1995, niet voldoende is om de op het moment van afstuderen vereiste startcompetentie te kunnen bereiken. De inhoud van de gedifferentieerde co-assistentschappen is te sterk op de 
werkzaamheden, kennis en vaardigheden van de praktiserende dierenarts gericht en te weinig op de kennis en vaardigheden die nodig zijn voor de andere sectoren van de diergeneeskunde. Vaardigheden voor de veterinaire volksgezondheid, veterinair wetenschappelijk onderzoek en bestuursen beleidsfuncties komen in Curriculum 1995 niet of onvoldoende aan bod. ${ }^{4}$ Het bovenstaande vormde de aanleiding voor de invoering van Curriculum 2001.

\section{Curriculum 2001}

Dit curriculum bouwt voort op Curriculum 1995. Het heeft twee nieuwe doelstellingen: a) een verdere academisering van het onderwijsprogramma en b) invoering van gescheiden studiepaden en studierichtingen. Deze doelstellingen worden nu afzonderlijk toegelicht.

\section{Academisering van het onderwijs- programma}

De student dient meer verantwoordelijkheid te krijgen voor het eigen studieprogramma, er ligt een sterker accent op zelfstudie en de hoeveelheid contactonderwijs wordt in vergelijking met Curriculum 1995 aanmerkelijk gereduceerd. Om de zelfstudie van studenten inhoudelijk te ondersteunen worden er aanwijzingen en vragen voor zelfstudie aangeboden en is er op van te voren geplande tijdstippen een docent beschikbaar. De zelfstudie wordt logistiek ondersteund door de inrichting van een facultair studielandschap en de introductie van de digitale leeromgeving WebCT.

Academisering betekent ook dat er in alle onderdelen van het curriculum aandacht wordt besteed aan de belangrijke vragen van het wetenschappelijk onderzoek op het betreffende gebied. Ook worden 'onzekerheden' op het vakgebied expliciet aan de orde gesteld.

\section{Invoering van gescheiden studiepaden/ studierichtingen}

In Curriculum 2001 wordt de diersoorten sectordifferentiatie uitgebreid van één naar twee studiejaren. De daarvoor benodigde ruimte wordt geschapen door reeds vanaf het eerste studiejaar gescheiden studiepaden in te richten. In de eerste twee studiejaren zijn er de studiepaden: 'Individueel gehouden dieren' en 'Veterinaire volksgezondheid/landbouwhuisdieren'. Vanaf het derde studiejaar worden deze studiepaden verder uitgesplitst. Deze differentiatie is gebaseerd op de inhoudelijke verschillen en overeenkomsten in de beroepsuitoefening met betrekking tot verschillende diersoorten en sectoren. De specifieke modules van het studiepad 'Bestuur en beleid' komen pas in het zesde studiejaar aan de orde. Studenten uit alle andere studiepaden kunnen in het zesde studiejaar het studiepad 'Bestuur en beleid' kiezen. Een overzicht van de studiepaden staat in tabel 1 .

Studenten kunnen afstuderen met één van de volgende uitstroomprofielen:

1. Dierenarts individueel gehouden dieren - gezelschapsdieren;

2. Dierenarts individueel gehouden dieren - paarden;

3. Dierenarts landbouwhuisdieren, met de optie om nader te differentiëren in herkauwers, varkens of pluimvee;

4. Dierenarts veterinaire volksgezondheid;

5. Dierenarts veterinair wetenschappelijk onderzoek;

6. Dierenarts bestuur en beleid.

Het kerncurriculum beslaat globaal vier jaar van de gehele opleiding en is voor alle studenten hetzelfde. Het heeft betrekking op 117 van de 168 studiepunten in de voorbereidende fase en 42 van de 84 punten in de functiegerichte fase (tabel 2). 
Tabel 1. Studiepaden in het curriculum diergeneeskunde.

\begin{tabular}{|c|c|c|c|c|c|}
\hline Studiejaar & \multicolumn{5}{|c|}{ Studiepaden } \\
\hline Jaar $1+2$ & \multicolumn{3}{|c|}{$\begin{array}{l}\text { Veterinaire volksgezondheid/ } \\
\text { landbouwhuisdieren }\end{array}$} & \multicolumn{2}{|c|}{ Individueel gehouden dieren } \\
\hline & & & & 1 & T \\
\hline Jaar 3 & \multicolumn{2}{|c|}{$\begin{array}{c}\text { Veterinaire volksgezondheid/ } \\
\text { landbouwhuisdieren }\end{array}$} & \multirow[b]{2}{*}{$\begin{array}{c}\text { Veterinair } \\
\text { wetenschappelijk } \\
\text { onderzoek }\end{array}$} & \multirow[b]{2}{*}{ Gezelschapsdieren } & \multirow[b]{2}{*}{ Paard } \\
\hline Jaar 4 & $\begin{array}{c}\text { Veterinaire } \\
\text { volksgezond- } \\
\text { heid }\end{array}$ & $\begin{array}{l}\text { Landbouw- } \\
\text { huisdieren }\end{array}$ & & & \\
\hline Jaar 5 & \multicolumn{5}{|c|}{ Uniforme co-assistentschappen en Onderzoeksstage } \\
\hline Jaar 6 & $\begin{array}{c}\text { Veterinaire } \\
\text { volksgezond- } \\
\text { heid }\end{array}$ & $\begin{array}{l}\text { Landbouw- } \\
\text { huisdieren }\end{array}$ & $\begin{array}{c}\text { Veterinair } \\
\text { wetenschappelijk } \\
\text { onderzoek }\end{array}$ & Gezelschapsdieren & Paard \\
\hline & & & /eterinair bestuur & eleid & \\
\hline
\end{tabular}

Tabel 2. Verdeling van de studiepunten over kerncurriculum, studiepaden en vrije keuzeruimte.

\begin{tabular}{lccc}
\hline Studiejaar & \multicolumn{3}{c}{ Studiepunten } \\
\cline { 2 - 4 } & Kerncurriculum & Studiepaden & Vrije keuzeruimte \\
\hline Voorbereidende fase & 37 & 5 & 0 \\
Eerste studiejaar & 32 & 8 & 2 \\
Tweede studiejaar & 24 & 14 & 4 \\
Derde studiejaar & 24 & 14 & 4 \\
Vierde studiejaar & & & 0 \\
Functiegerichte fase & 42 & 0 & 0 \\
Vijfde studiejaar & 0 & 42 & 10 \\
Zesde studiejaar & 159 & 83 & \\
\hline Totaal & & &
\end{tabular}

De doelstelling van het kerncurriculum is om studenten het brede diersoortoverschrijdende pathobiologische inzicht bij te brengen, dat de dierenarts juist onderscheidt van andere biomedisch geschoolden. Tevens wordt door het kerncurriculum, met name door de daarin opgenomen uniforme co-assistentschappen, blijvend inhoud gegeven aan de algemene bevoegd- heid van de dierenarts zoals vastgesteld in de richtlijnen van de Europese Unie. ${ }^{5}$

Naast het kerncurriculum zijn er de specifieke onderdelen van de verschillende studiepaden. Hierin wordt verdieping aangebracht in de theoretische kennis en de vaardigheden die belangrijk zijn voor de betreffende diersoorten of sector. 


\section{Globale uitwerking van Curriculum 2001}

Uitgaande van de inhoud en de opzet van Curriculum 1995 is voor ieder vak of onderdeel bekeken of en zo ja voor welke studiepaden en in welke omvang een deel van het vak studiepadspecifiek dient te worden ingevuld. Door het facultaire onderwijsbestuur is per studiepad advies gevraagd aan een panel van experts op het gebied van de betreffende diersoort(en) of sector. Een overzicht van de verdeling in kern- en studiepadspecifiek curriculum is gegeven in tabel 2.

Bij nagenoeg alle vakken beslaat het kerncurriculum een groter gedeelte dan de studiepadspecifieke onderdelen. Voor veel vakken geldt dat hun bijdrage aan de verschillende studiepaden even groot is. Een aantal vakken is echter wat betreft inhoud en vaardigheden sterk gebonden aan een bepaalde diersoort of sector en daarmee voor sommige studiepaden belangrijker dan voor andere. Bij deze vakken varieert de omvang van het studiepadspecifieke onderwijs per studiepad. Hoe de verdeling van kern- en studiepad- specifiek curriculum er op vakniveau uit kan zien wordt geillustreerd aan de hand van enkele voorbeelden in tabel 3 .

\section{Studiepadkeuze}

Ten aanzien van de keuze van een studiepad in het eerste studiejaar zijn twee groepen studenten te onderscheiden. Met ingang van het studiejaar 2001-2002 wordt $30 \%$ van de eerstejaars studenten toegelaten via decentrale selectie. De doelstelling van de decentrale selectie diergeneeskunde is studenten te werven voor de minder bekende en dientengevolge minder populaire sectoren 'Landbouwhuisdieren' en 'Veterinaire volksgezondheid'. Met studenten die via decentrale selectie tot de studie worden toegelaten maakt de faculteit voor aanvang van de studie een schriftelijke afspraak dat zij zich binden aan het studiepad 'Landbouwhuisdieren' of 'Veterinaire volksgezondheid'.

De andere studenten worden geplaatst via de categorie ' 8 of hoger' of via loting. Aan het einde van het eerste trimester dienen zij één van de twee studiepaden te

Tabel 3. Voorbeeld van verdeling kern-en studiepadspecifiek curriculum op vakniveau.

\begin{tabular}{|c|c|c|c|c|c|c|c|}
\hline & \multicolumn{7}{|c|}{ Studiepunten } \\
\hline & \multicolumn{3}{|c|}{$\begin{array}{c}\text { microbiol. }^{a} \\
\text { jaar }\end{array}$} & \multicolumn{2}{|c|}{$\begin{array}{c}\text { adapfys.b } \\
\text { jaar }\end{array}$} & \multirow{2}{*}{$\begin{array}{l}\text { alg. heelk.c } \\
\text { jaar } \\
4\end{array}$} & \multirow{2}{*}{$\begin{array}{c}\text { bedrijfsdierg.d } \\
\text { jaar } \\
4\end{array}$} \\
\hline & 2 & 3 & 4 & 2 & 3 & & \\
\hline Kerncurriculum & 7 & & & 1 & 1 & 3 & 2 \\
\hline \multicolumn{8}{|l|}{ Studiepaden } \\
\hline Vet. volksgez./landbouwhuisdieren & & & & 0.5 & 1.5 & & \\
\hline Vet. volksgezondheid & & & 3 & & & & 1.5 \\
\hline Landbouwhuisdieren & & & & & & 1 & 1.5 \\
\hline Gezelschapsdieren & & & & & 1 & 2 & 1 \\
\hline Paard & & & & & 1 & 2 & 1 \\
\hline Vet. wetensch. onderzoek & 4 & & & & 1 & & \\
\hline \multicolumn{8}{|c|}{ a Microbiologie/immunologie } \\
\hline \multicolumn{8}{|c|}{$\begin{array}{l}\text { b Adaptatiefysiologie: betreft de eisen die het dier aan zijn omgeving stelt, uitgaande van domesticatieprincipes, met expliciete aandacht } \\
\text { voor welzijnsaspecten. } \\
\text { c Algemene heelkunde is gericht op basale chirurgische kennis en vaardigheden. } \\
\text { d Inleiding in de bedrijfsdiergeneeskunde/economie van de dierhouderij, betreft de basisprincipes van de bedrijfsadvisering in relatie tot } \\
\text { de economische aspecten van het landbouwbedrijf. }\end{array}$} \\
\hline
\end{tabular}


kiezen. Om een goed onderbouwde keuze mogelijk te maken is in het eerste trimester het vak inleiding in de diergeneeskunde opgenomen. Hierin komen alle sectoren van de diergeneeskunde aan bod. De schriftelijk beargumenteerde studiepadkeuze van de eerstejaarsstudent maakt deel uit van de beoordeling voor dit vak.

Aan het einde van de propedeusefase worden alle studenten door de examencommissie voor de propedeuse bindend verwezen naar de relevante studiepaden in de doctoraalfase. ${ }^{6}$

\section{Aansluiting op het beroepsveld}

$\mathrm{Na}$ de zesjarige opleiding diergeneeskunde is de afgestudeerde dierenarts 'algemeen bevoegd', maar niet 'algemeen bekwaam'. 37 De pas afgestudeerde dierenarts heeft een startcompetentie voor de diersoort(en) of de sector waarvan het studiepad is doorlopen. Slechts een zeer beperkt aantal dierenartsen doorloopt een aansluitend vierjarig opleidingstraject tot specialist (met name gericht op disciplines binnen 'Gezelschapsdieren' en 'Paard'). Recent is een erkenningsregeling opgezet door verschillende 'Groepen' in de beroepsvereniging Koninklijke Nederlandse Maatschappij voor Diergeneeskunde $(\mathrm{KNMvD})$ in samenwerking met de landbouworganisaties (LTO-Nederland) en de verzekeringsmaatschappijen. ${ }^{8}$ Op dit moment zijn er erkenningsregelingen voor herkauwers-, varkens-, pluimvee- en paardengeneeskunde ontwikkeld en geïmplementeerd. Een erkenningsregeling voor de sector veterinaire volksgezondheid en voor de gezelschapsdiergeneeskunde is in voorbereiding. Om bijvoorbeeld werkzaam te kunnen zijn in de bedrijfsbegeleiding van melkveehouderijbedrijven dient de dierenarts een minimum aantal uren te werken in deze sector en jaarlijks een minimum aantal 'punten' nascholing gevolgd te hebben. Alvorens erkend te kunnen worden dienen dierenartsen een bepaalde tijd in de desbetreffende sector/diersoort werkzaam te zijn onder begeleiding van een 'tutor'. Bij het vaststellen van deze tijd wordt rekening gehouden met het in de studie doorlopen studiepad. De afgestudeerde dierenarts die werkzaam wil zijn in een andere sector dan die van het door hem/haar doorlopen studiepad zal een langdurig en intensief bijscholingstraject dienen te doorlopen om voor een erkenning voor die sector in aanmerking te kunnen komen. De Faculteit Diergeneeskunde en de KNMvD hebben bij de opzet en uitwerking van Curriculum 2001 en de erkenningsregelingen intensief overleg gevoerd en de plannen op elkaar afgestemd.

\section{Discussie}

De Faculteit Diergeneeskunde denkt met de invoering van gescheiden studiepaden in het curriculum diergeneeskunde adequaat in te spelen op de behoeftes in het beroepsveld met betrekking tot de voortschrijdende differentiatie naar diersoorten en sectoren en op de behoefte aan dierenartsen die op een academische wijze in staat zijn de complexe problemen in de diverse sectoren van het beroepsveld adequaat aan te pakken en op te lossen.

$\mathrm{Er}$ is een evaluatie in voorbereiding waarbij nagegaan zal worden of afgestudeerde dierenartsen vinden dat de doelstellingen van Curriculum 1995 verwezenlijkt zijn. Tevens worden de onderdelen van Curriculum 2001 intensief geëvalueerd. De resultaten van deze evaluatie kunnen leiden tot een verdere evolutie van Curriculum 2001.

Opzet, implementatie en evaluatie van een curriculum diergeneeskunde met gescheiden studiepaden kan mogelijk interessante gegevens opleveren voor andere medische opleidingen waar een differentiatie binnen het curriculum wordt overwogen. 


\section{Literatuur}

1. Dijk C van, Vries B de. Arbeidsmarktonderzoek voor veterinair opgeleiden. Instituut voor Toegepaste Sociale Wetenschappen; 1988.

2. Curriculum Diergeneeskunde: Eindrapport curriculum Commissie. Utrecht: Faculteit der Diergeneeskunde; December 1993.

3. Beukelen P van, Golde LMG van. Het nieuwe curriculum Diergeneeskunde in Utrecht. Mediator 1998;9:32-7.

4. Diergeneeskunde in 2000: een studie met aparte studierichtingen. Startnotitie over de toekomst van de Faculteit der Diergeneeskunde. Utrecht: Faculteit der Diergeneeskunde; 1994.

5. EU-richtlijn 78/1027/EEG. Pbl. EGL 362. 1978.

6. De Onderwijs-en Examenregeling Diergeneeskunde, ex. Artikel 7.13 van de wet op het Hoger en Wetenschappelijk Onderwijs. 27 juni 2001.

7. Onderwijsbestuur Diergeneeskunde. Curriculum 2001: voorstellen voor een verdere academisering van het curriculum Diergeneeskunde en evolutie naar gescheiden studiepaden. Utrecht: Faculteit der Diergeneeskunde; 25 mei 2000.

8. Instroomeisen erkenningsregeling: notitie van Coördinatiecentrum Erkende Dierenartsen. Utrecht: Coördinatiecentrum Erkende Dierenartsen; 12 april 2001.
De auteurs:

Dr. P. van Beukelen, onderwijsdirecteur, Afdeling Onderwijs- en Studentenzaken.

Drs. D. Wesseling, stafmedewerker onderwijs, Afdeling Onderwijs-en Studentenzaken.

Drs. J.C.M. Haarhuis, onderwijscoördinator, Afdeling Onderwijs- en Studentenzaken.

Prof. dr. L.M.G. van Golde, voorzitter Onderwijsbestuur, hoogleraar biochemie, Hoofdafdeling Biochemie, Celbiologie en Histologie.

Allen zijn werkzaam bij de Faculteit der Diergeneeskunde, Universiteit Utrecht.

Correspondentieadres:

Dr. P. van Beukelen, onderwijsdirecteur, Afdeling Onderwijs- en Studentenzaken, Faculteit der Diergeneeskunde, Universiteit Utrecht, Postbus 80163, 3508 TD Utrecht, tel.030-2533703,p.vanbeukelen@vet.uu.nl.

\section{Summary}

Introduction: In veterinary practice differentiation by species and sector is increasing. Veterinary medicine of individually kept animals (companion animals and horses) is focused on curative aspects, while in farm animals (dairy cattle, pigs, poultry) herd health management and veterinary public health aspects are dominant. These changes have prompted the restructuring of the curriculum of the Faculty of Veterinary Medicine in Utrecht, the Netherlands.

Description: In the restructured curriculum introduced in 1995, species-oriented differentiation was limited to sixth year. In September 2001 a new curriculum was introduced with more emphasis on academic development and more differentiation through the introduction of study tracks. In the first two years students follow one of two tracks: 'individually kept animals' or 'farm animals/veterinary public health'. These tracks are further subdivided from year three onwards. There are six graduation profiles. Credit points are distributed over the core curriculum, study tracks and electives, with 159, 83 and 10 credit points, respectively. Examples illustrate how credit points for different subjects are distributed over core curriculum and study tracks.

The veterinary public health/farm animals track is obligatory for students admitted through the decentralised admissions procedure. The other students select a track after three months.

The professional organisation has introduced species-oriented and sector-oriented certification with study-track related entrance requirements.

Discussion: The Faculty of Veterinary Medicine is convinced that the new curriculum will meet the changed requirements of veterinary practice. Both Curriculum 1995 and Curriculum 2001 will be evaluated. Differentiation through study tracks may set an example for other medical curricula. (Beukelen P van, Wesseling D, Haarhuis JCM, Golde LMG van. Differentiation in veterinary medical education through study tracks. Dutch Journal of Medical Education 2002;21(4):154-160.) 